\title{
Adequate Yearly Progress in Small Rural Schools and Rural Low-Income Schools
}

\author{
Thomas W. Farmer \\ National Research Center on Rural Education Support \\ Man-Chi Leung \\ Center for Developmental Science \\ Jonathan Banks \\ National Research Center on Rural Education Support \\ Victoria Schaefer \\ National Research Center on Rural Education Support \\ Bruce Andrews \\ National Research Center on Rural Education Support \\ Robert Allen Murray \\ National Research Center on Rural Education Support
}

\begin{abstract}
Adequate yearly progress (AYP) on No Child Left Behind criteria was examined for a randomly selected sample of districts that qualify for the Rural Education Achievement Program (REAP). The sample involved 10\% of districts that were eligible for the Small Rural Schools Achievement (SRSA) program and 10\% that were eligible for the Rural and Low-income Schools (RLIS) program. Based on district reports, nearly $80 \%$ of SRSA schools made AYP, $11 \%$ failed, and $11 \%$ did not have adequate data. For schools in the RLIS program, districts reported that 65\% made AYP, 29\% failed, and $6 \%$ did not report adequate data. The SRSA and RLIS samples had different patterns for the categories of students that did not make AYP. Also, SRSA and RLIS districts were differentially distributed across the United States. Implications for interventions are discussed.
\end{abstract}

The No Child Left Behind Act of 2001 (NCLB) was established by the federal government to enhance academic proficiency by mandating that states and local education agencies develop accountability systems to assess student achievement and educational improvement (No Child Left Behind Act of 2001). A primary emphasis of this legislation is to ensure that schools focus on the progress of subsamples of the school population who have traditionally performed less well in school (Smith, 2005). Accordingly, schools must conduct annual assessments that involve separate measurable objectives to examine the proficiency and improvement of all students and specific groups of students who may be at increased risk for lower rates of academic achievement. These groups include economically disadvantaged students, students from major racial and ethnic groups, students with disabilities, and students with limited English proficiency. The annual academic assessments of student achievement are used to determine whether public schools are making adequate yearly progress (AYP) toward enabling all students to meet the state's academic achievement standards and narrowing the academic achievement gap. While the ultimate aim is that all students in each group will meet or exceed a state's proficient level of academic achievement by 2014, each state must establish a timeline and intermediate goals to meet this requirement. A school is deemed as not making AYP if the assessment scores for the entire student body or for any specific subgroup do not meet the state objectives for reading and mathematics or a group does not show annual improvement (i.e., the percentage of students in the group who did not meet proficiency decreases by 10\% from the previous year) (No Child Left Behind Act of 2001).

Within the NCLB legislation the Rural Education Achievement Program (REAP) was established to provide additional funding to help schools address challenges that are unique to rural districts (Hill \& Kusler, 2004; No Child Left Behind Act of 2001). More specifically, REAP provides financial assistance to the most challenged rural districts in the country, those "that may lack the personnel and resources to compete effectively for Federal competitive grants”, among other specified criteria (No Child Left Behind Act of 2001). Thus, schools eligible to participate in REAP make up only a segment of rural schools in America, those that are among the most challenged by the demands of No Child Left Behind. Still, in the 2002-2003 school year for example, this segment of rural schools served nearly 4.5 million rural children, or almost $10 \%$ of America's schoolage population. REAP distributes funding generally through 
two program areas, which recognize the diversity of rural areas and communities - a) the Small, Rural School Achievement Program (SRSA), which served up to 1.6 million students in 9,345 schools, and b) the Rural and LowIncome School Program (RLIS), which served up to 2.85 million students in 6,607 schools (Johnson, 2004). To qualify for the SRSA program a school district must be located in a county with fewer than 10 people per square mile or have fewer than 600 students in average daily attendance and all schools in the district must be in communities with a school locale code of 7 or 8 (i.e., have fewer than 2,500 residents). To qualify for the RLIS program, at least $20 \%$ of the students must be from families below the poverty line and all schools in the district must be designated with a school locale code of 6, 7, or 8 (i.e., be in a non-metropolitan town that has a population of less than 25,000 residents).

While acknowledging that the goals of NCLB are laudable, many school administrators, teachers, rural education leaders, and agencies have expressed concern that the requirements of the legislation are particularly challenging for rural schools (American Association of School Administrators, 2003; Coladarci, 2003; Jimerson, 2004; National Rural Education Association, 2004; United States Government Accountability Office, 2004). In light of these concerns, there is a need to examine how rural schools are doing during the initial implementation of the NCLB criteria, particularly those rural schools that are considered among the most challenged (i.e., those eligible for REAP). To address this need, the goal of the current study was to examine AYP for a random sample of REAP-eligible schools.

To examine the progress of REAP-eligible schools, this study was guided by three specific aims. The first aim was to determine the percentage of SRSA-eligible and RLISeligible schools that made AYP. The second aim was to determine whether SRSA-eligible and RLIS-eligible schools had difficulty supporting the proficiency of specific subgroups of students, and, if so, to identify those specific subgroups. The third aim was to examine differences in the characteristics of SRSA-eligible and RLIS-eligible schools on key factors including geographical location, proportion of youth from ethnic minorities, proportion of youth eligible for free or reduced lunch, and student/teacher ratio. Information obtained from these analyses may help to promote the development of interventions to support rural schools as they work to meet the requirements of NCLB.

\section{Method}

\section{Sampling}

To address the first two research aims, this study included two samples of randomly selected school districts that qualified for the Rural Education Achievement Program in 2003-2004. The SRSA sample consisted of 466 schools in 348 districts in 36 states, while the RLIS-eligible sample consisted of 468 schools in 128 districts in 28 states. To address the third aim of this study, analyses were conducted with an extant data base of the demographic characteristics of all SRSA and RLIS eligible schools (15,952 schools) for 2002-2003.

\section{Measures}

Adequate Yearly Progress (AYP). NCLB requires each state to administer statewide language arts and math tests to students and set a specific score on the tests that indicates whether students are proficient in these two areas at their grade level. With the proficient rate at 2002 used as the baseline, the state sets targets for increasing the percentage of students who are proficient in each subsequent year. The proficient rate is measured not only for the student body of the school as a whole, but also for subgroups of students in the school: students with limited English proficiency; students from low-income families; students with disabilities; and students from each major racial/ethnic group (Asian, African American, Alaska Native, Hispanic, Caucasian and Native American). To be considered as making AYP, the school must meet the preset proficient rate in both language arts and math calculated for the school as a whole and also for each aforementioned subgroup. In addition, at least $95 \%$ of the students enrolled in school must take the tests, as well as $95 \%$ of students within each subgroup.

\section{Procedures}

To address the first two aims of this study, SRS and RLIS samples were randomly selected from the universe of REAP schools. First, all REAP-eligible districts for the 2004-2005 school year were identified using information available from the U.S. Department of Education's REAP website (http://www.ed.gov/nclb/freedom/local/reap.html); 4815 districts were identified as SRSA-eligible and 1126 districts were identified as RLIS-eligible. To randomly select districts for inclusion in this study, an arbitrary identification number was assigned to each school district. Two random number lists, one for SRSA-eligible districts and one for RLIS-eligible districts, were generated. $10 \%$ of all SRSA-eligible school districts and $10 \%$ of all RLISeligible school districts were identified for the samples. Once the sample districts were identified, all schools providing any $1^{\text {st }}$ to $8^{\text {th }}$ grade education in the selected districts were included. A small portion of the originally identified districts did not have schools that served students in grades 1-8 or did not have data about AYP. Information on whether or not a school made AYP, as well as the participation rates and the proficient rates in the language arts and math, was collected primarily from State Department of Education websites for each respective state. If the information was not available at this site, a research 
assistant looked at the specific school district website or contacted district officials by telephone to obtain the information. AYP data was sought for the most recent school year. In most instances, AYP information was available for 2003-2004. In some cases, however, the most recent data were for the 2002-2003 school year.

With regard to aim three, a data set containing a list of all REAP-eligible schools for the 2002-2003 school year was examined (Johnson, 2004). Upon identification of regional trends based on SRSA versus RLIS Program participation, further analysis was conducted to identify differences in ethnicity, free or reduced lunch program participation rates, and student-teacher ratios.

\section{Results}

\section{Percentage of Schools Making AYP}

SRSA sample. Three hundred and sixty four schools (78.1\%) made AYP while 50 schools (10.7\%) failed to make AYP. Fifty two schools (11.2\%) in the sample did not have adequate data. (Table

Table 1.

Percentage of SRSA Schools Made and Failed to Make AYP

\begin{tabular}{lccc}
\hline AYP Status & Count & $\begin{array}{l}\text { Percentage } \\
\text { Of Schools }\end{array}$ & $\begin{array}{c}\text { Valid } \\
\text { Percentage }\end{array}$ \\
\hline Made AYP & 364 & $78.1 \%$ & $87.9 \%$ \\
Failed to make AYP & 50 & $10.7 \%$ & $12.1 \%$ \\
No data & 52 & $11.2 \%$ & - \\
Total & 466 & $100.0 \%$ & $100.0 \%$ \\
\hline
\end{tabular}

RLIS sample. Three hundred and five schools (65.2\%) Twenty seven schools (5.8\%) in the sample did not have made AYP while 136 schools (29.1\%) failed to make AYP. adequate data. (Table 2)

Table 2.

Percentage of RLIS Schools Made and Failed to Make AYP

\begin{tabular}{lccc}
\hline AYP Status & Count & $\begin{array}{c}\text { Percentage } \\
\text { Of Schools }\end{array}$ & $\begin{array}{c}\text { Valid } \\
\text { Percentage }\end{array}$ \\
\hline Made AYP & 305 & $65.2 \%$ & $69.2 \%$ \\
Failed to make AYP & 136 & $29.0 \%$ & $30.8 \%$ \\
No data & 27 & $5.8 \%$ & - \\
Total & 468 & $100.0 \%$ & $100.0 \%$ \\
\hline
\end{tabular}

Subgroup Performance in Schools that Failed to Make AYP

Further analyses were conducted to examine performance of subgroups in schools that failed to make AYP. For each subgroup, we counted the percentage of schools that failed one or more of the following requirements: 95\% participation rate in tests, proficiency rate in language arts test, and proficiency rate in math test, preset by state.
SRSA sample. Of the 50 schools that failed to make AYP, 31 of them (62.0\%) failed in one or more of the requirements when the whole school was considered. Three subgroups had a relatively high rate of failing one or more requirements: students with low income (42.0\%), Alaskan native students (26.0\%) and students with limited English proficiency (20.0\%). All other subgroups had less than $10 \%$ of its schools not making the requirements. (Figure 1) 


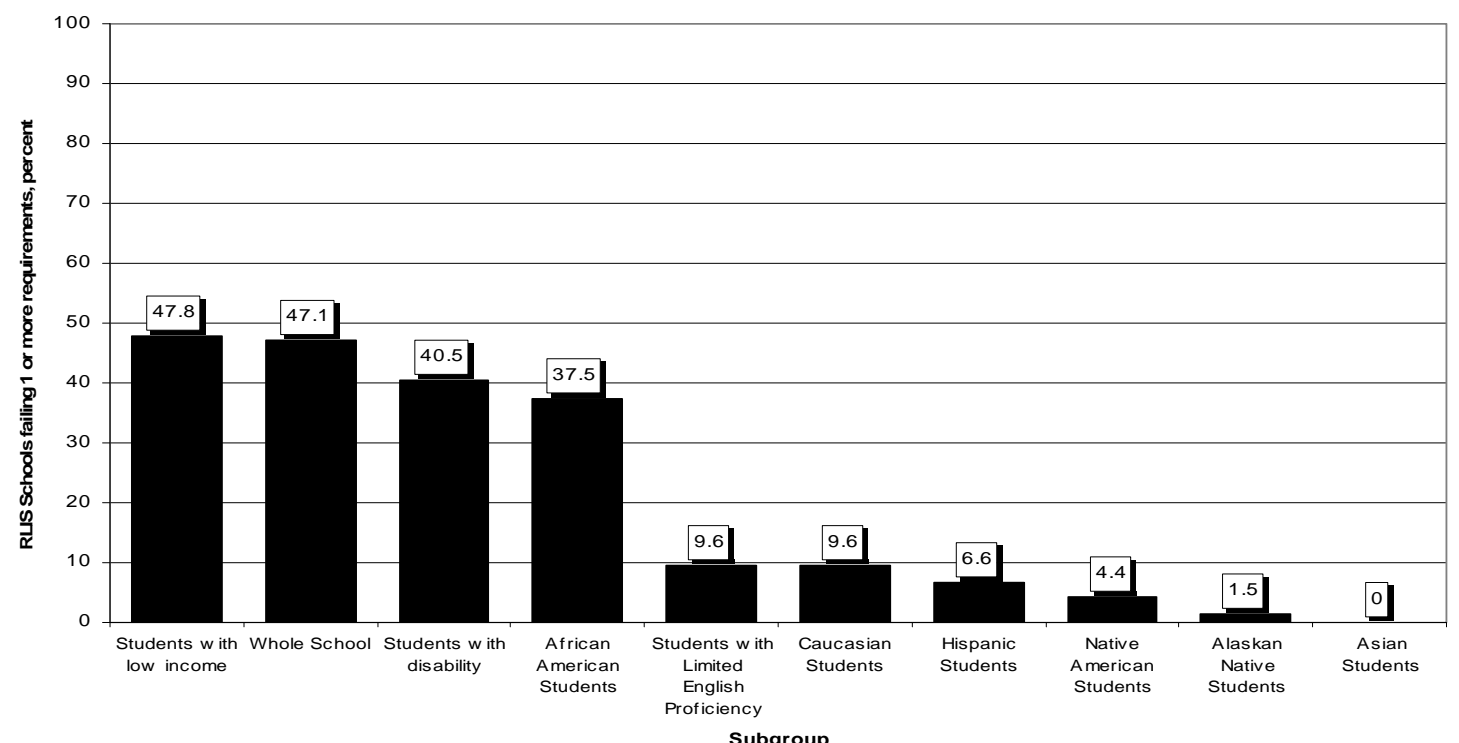

Subgroup

Figure 1. Percent of SRS Schools failing one or more requirements by subgroup.

RLIS sample. Of the 136 schools that failed to make AYP, 64 of them $(47.1 \%)$ failed in one or more of the requirements when the whole school was considered. The subgroup of students with low income, with a rate of $47.8 \%$, was the top subgroup in failing one or more requirements.
Two other subgroups also had a high failing rate: students with disability (40.5\%) and African American students (37.5\%) All other subgroups had less than $10 \%$ of its schools fail one or more requirements. (Figure 2)

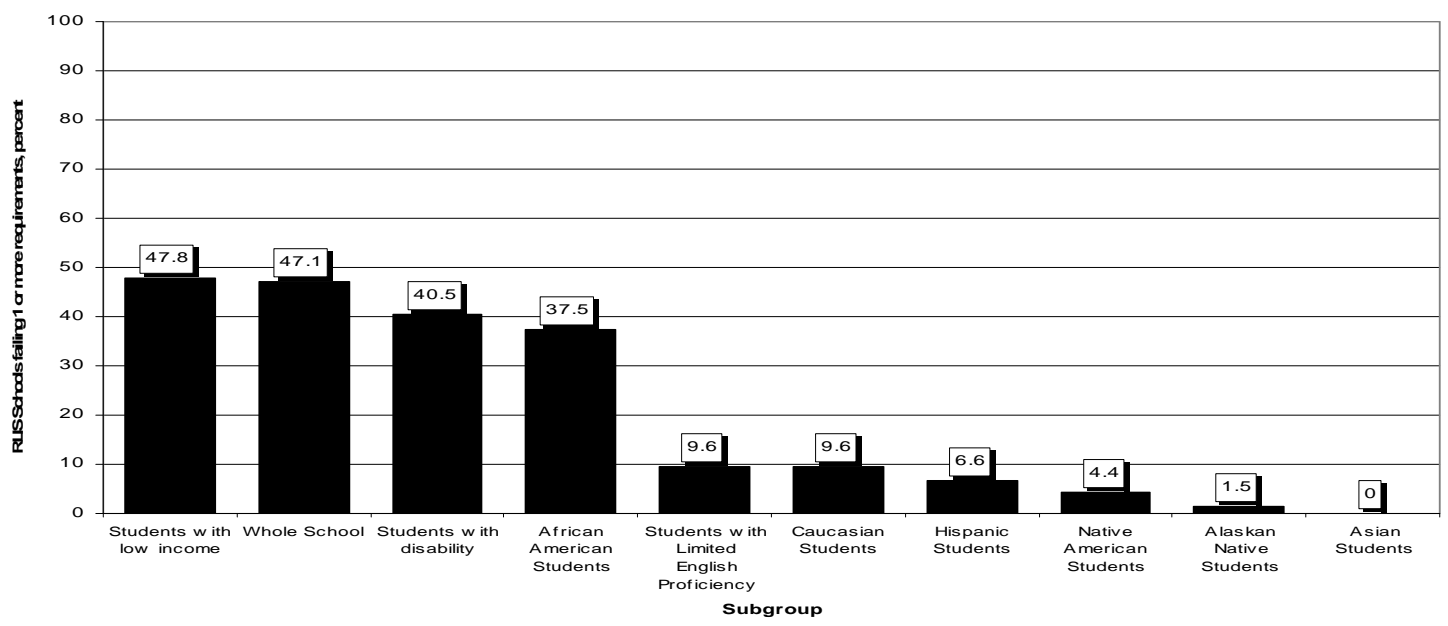

Figure 2. Percent of RLIS schools failing one or more requirements by subgroup.

\section{Differences in the Characteristics of SRSA and RLIS Schools}

Geographical location. Regional trends were identified in REAP-eligible schools. For the SRSA schools, two- thirds were concentrated in 31 states. These states were primarily in the northern and central regions of the United States (see figure 3). For the RLIS schools, over $80 \%$ were located in 16 southern states (see figure 4). 


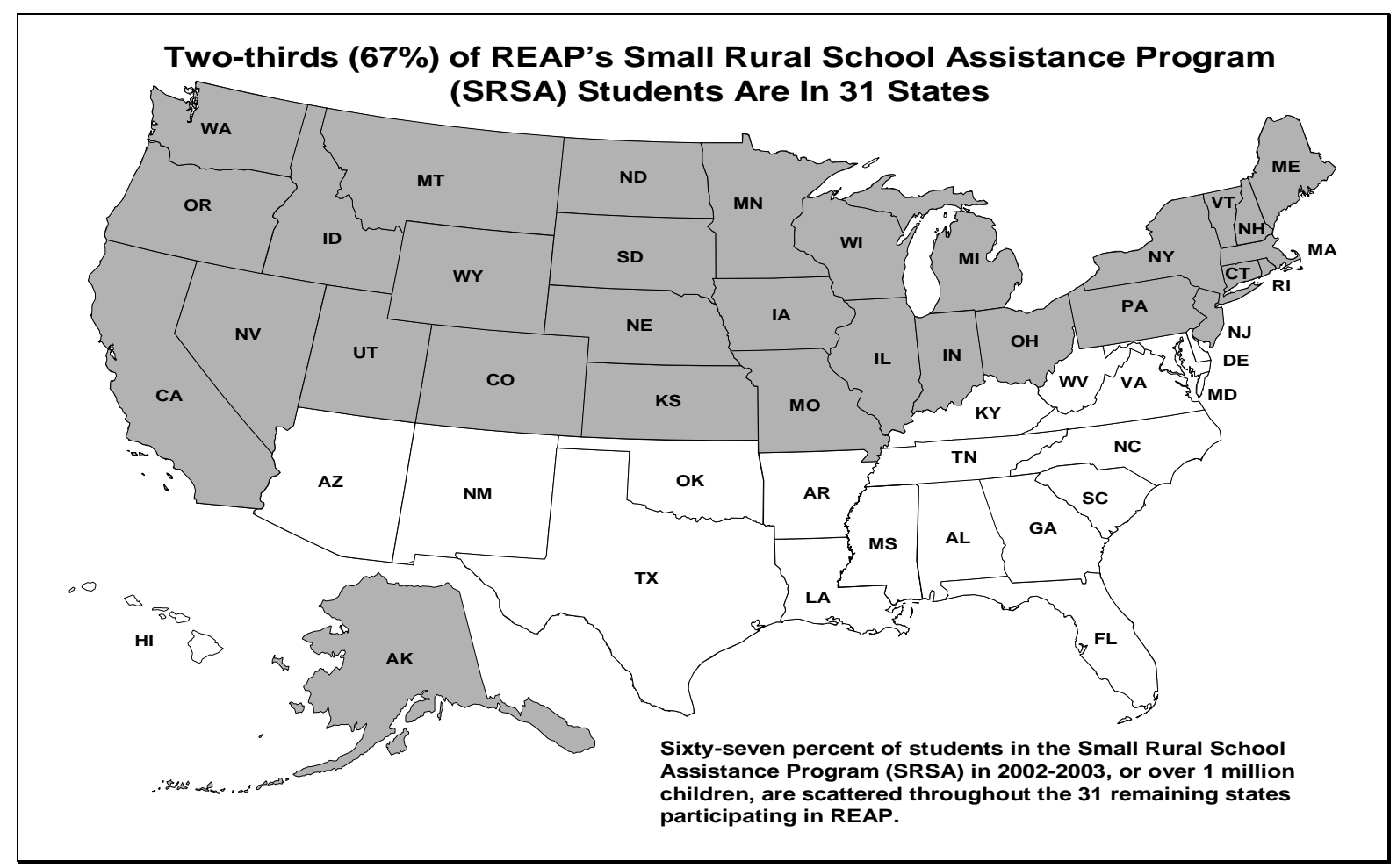

Figure 3. Distribution of SRSA schools.

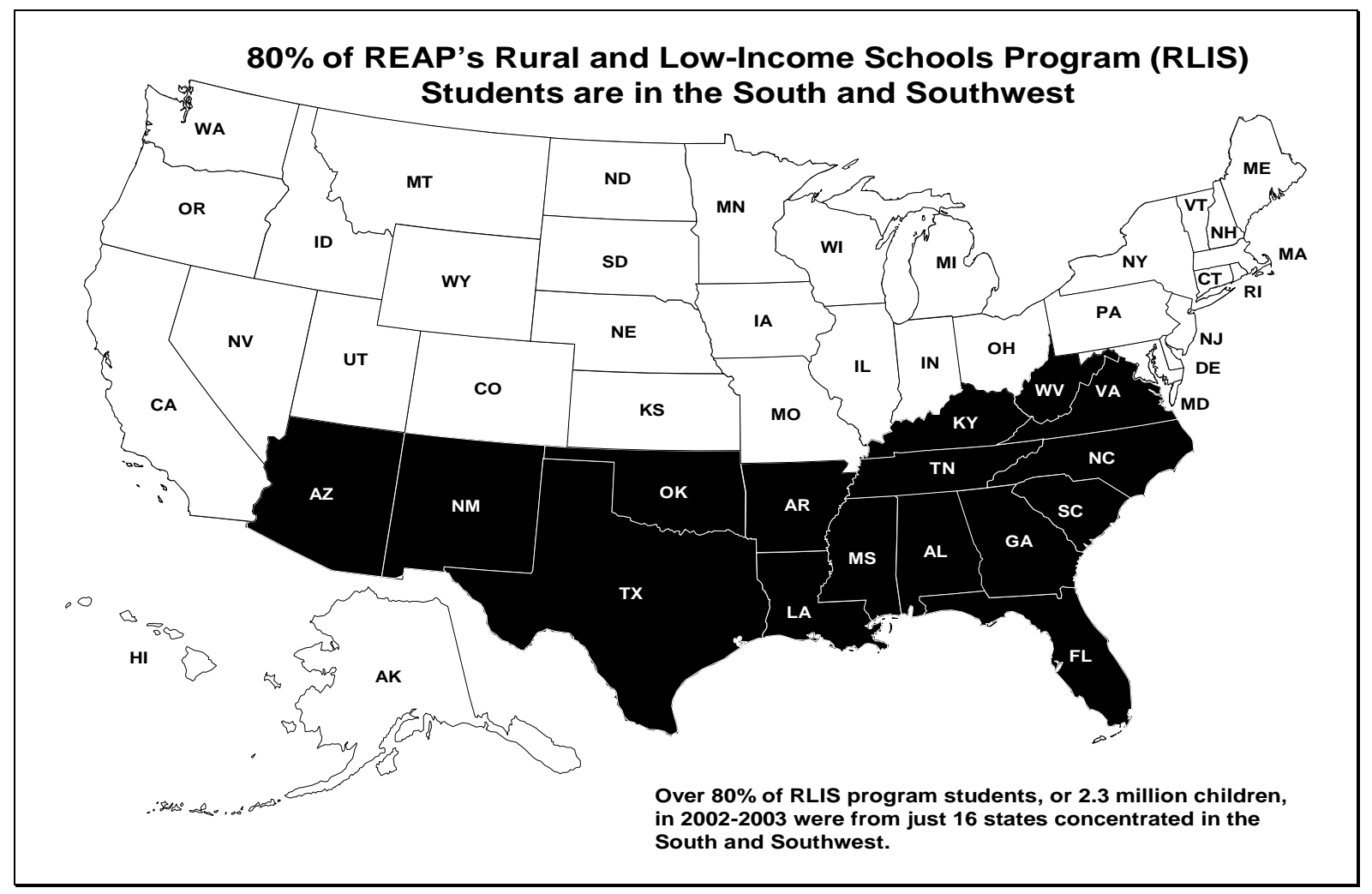

Figure 4. Distribution of RLIS schools. 
Key school characteristics. The SRSA and RLIS schools were compared in terms of percentage of minority youth, percentage of youth receiving free and reduced lunch, and the ratio of students to teachers. As shown in Table 3, RLIS schools had a significantly higher percentage of youth from ethnic minorities (37\% vs. 20\%) than did SRSA schools and they also had a higher percentage of students receiving free and reduced lunch (62\% vs. 43\%). Additionally, the RLIS schools had higher student to teacher ratios (15.2 vs. 12.6).

Table 3.

Differences Between SRSA and RLIS Schools on Key Characteristics

\begin{tabular}{|c|c|c|c|c|c|}
\hline & SRSA & RLIS & & & \\
\hline & $M(S D)$ & $M(S D)$ & $t$ & $d f$ & $p$ \\
\hline Minority (\%) & 19.61(27.25) & $37.22(32.55)$ & -36.572 & 15600 & $<.001$ \\
\hline Free/reduced lunch (\%) & $42.63(22.47)$ & 61.85(22.32) & -51.860 & 15081 & $<.001$ \\
\hline Pupil to teacher ratio & $12.62(10.06)$ & $15.22(5.49)$ & -18.675 & 15475 & $<.001$ \\
\hline
\end{tabular}

\section{Discussion}

The results of this study suggest that the majority of rural schools that are eligible for the Rural Education Achievement Program (REAP) are making adequate yearly progress on No Child Left Behind criteria. Overall, 72\% of the rural schools in this random sample made AYP, 20\% failed, and $8 \%$ did not report adequate data. However, the data also indicate a broad range in the performance of rural schools that appear to be related to both geographical differences and differences in the populations of students served.

One of the major challenges in rural education research is the high degree of diversity in the characteristics and needs of rural schools throughout the United States (Johnson \& Strange, 2005; Sherwood, 2000). Consistent with this view, the present study suggests that there is considerable variability in the adequate yearly progress of rural schools and that there are differences in the performance of school that qualify for the Small Rural Schools Achievement (SRSA) program and schools that qualify for the Rural and Low-Income Schools (RLIS) program. Compared to RLIS schools, a higher proportion of SRSA schools made AYP and a lower proportion failed.

Differences between SRSA and RLIS schools were most pronounced in terms of the proportion of reporting schools that failed to make AYP. Only $12 \%$ of reporting SRSA schools failed as compared to $31 \%$ of RLIS schools. Other differences were evident in the categories that schools failed on. Of the SRSA schools that failed to make AYP, $62 \%$ failed at the level of the whole school, $42 \%$ failed for lowincome students, 26\% failed for Alaskan Native students, and $20 \%$ failed for English Language Learners. Of the RLIS schools that failed to make AYP, $48 \%$ failed for lowincome students, $47 \%$ failed for the whole school, $41 \%$ failed for special education students, and $38 \%$ failed for African American students.

SRSA and RLIS schools are also different in terms of student demographics and the ratio of students per teacher. RLIS schools serve almost twice as many students from ethnic minorities as SRSA schools (37\% vs. $20 \%$ ) and they have a significantly higher proportion of students who receive free or reduced lunch (62\% vs $43 \%$ ). Also, RLIS schools have a significantly higher ratio of students per teacher (15.2 vs. 12.6). These differences are consistent with the differences in AYP between SRSA and RLIS schools and they suggest that RLIS schools may have a higher concentration of students who are at-risk for academic difficulties and fewer personnel to meet the needs of the students that they serve.

The results of this study may have important implications for the development of interventions and 
policies aimed at improving the academic outcomes of rural youth. First, as others have suggested (e.g., Jimerson, 2004; Johnson \& Strange, 2004; Sherwood, 2000), the tremendous diversity in the characteristics, resources, and needs in rural schools across the United States make it impractical to identify universal approaches to improve student performance. Rather, there is a need to develop flexible interventions and policies that help schools be responsive to the particular needs of their students and communities in relation to their available resources and circumstances. Second, there is a need to consider different approaches to supporting struggling schools in relation to the area in which they are experiencing difficulty. For example, in circumstances where the whole school is not meeting AYP there may be a need to reconsider the curriculum or to provide more training and support for teachers in general. In other circumstances it may be necessary to establish a concentrated focus on a specific population of students (i.e., African American students, native Alaskan students, students with disabilities, and English language learners). Consequently, there is a need for research on interventions that specifically focus on these various populations in diverse rural areas. Third, the impact of poverty on student performance appears to be pervasive and is evident in both SRSA and RLIS school districts. There is a need for research that focuses on clarifying how poverty constrains student performance in rural schools and on developing interventions that explicitly address the educational needs of impoverished rural youth. Fourth, there appear to be distinct differences in the issues and needs of SRSA and RLIS schools. SRSA schools may be more likely to experience difficulties that are related to geographical isolation. In contrast, RLIS schools appear to experience more difficulties that are related to serving high concentrations of students who are at-risk of low achievement.

In conclusion, it appears that many rural schools that qualify for the Rural Education Achievement Program are making adequate yearly progress during the early implementation of No Child Left Behind. However, a substantial proportion of these schools are not. As efforts move forward to enhance the educational outcomes of rural youth, it is necessary to recognize the diverse needs of rural communities and to establish programs that can be responsive to the various issues that schools experience. Issues related to geographical isolation, poverty, and high concentrations of students who are at-risk for academic difficulties should be a priority in the development of interventions and policies to improve the performance of students in REAP eligible schools. Yet, it must be recognized that the current study is limited to a focus on SRSA and RLIS schools. These programs serve only a small proportion of rural schools and students. There is a need for additional research to examine the performance of rural schools that are not eligible for REAP and to identify the challenges that they face and the supports that they need.

\section{References}

American Association of School Administrators. (2003). No child left behind: A guide for small and rural districts. Arlington, VA: Author.

Coladarci, T. (2003). Gallop goes to school: The importance of confidence intervals for evaluating "adequate yearly progress" in small schools (The Rural Schools and Community Trust). Washington, D.C.: The Rural Schools and Community Trust.

Hill, M. \& Kusler, M. (2004). No Child Left Behind and Rural Education: Implications for policy and practice. National Association of State Boards of Education and America Association of School Administrators: Alexandria, VA.

Jimerson, L. (2004). The devil is in the details: Ruralsensitive best practices for accountability under no child left behind (The Rural Schools and Community Trust). Washington, D.C.: The Rural Schools and Community Trust.

Johnson, J. (2004). Unpublished. 2002-2003 REAP data: National compilation. Arlington, VA: The Rural School and Community Trust.

Johnson, J. \& Strange, M. (2005). Why rural matters 2005: The facts about rural education in the 50 states. Arlington, VA: Rural School and Community Trust.

National Rural Education Association. (2004). Critical issues in rural education position paper I: "No child left behind." Norman, OK: Author.

No Child Left Behind Act of 2001, Pub. L. No. 107-110,115 Stat. $1425 \quad$ (2002) (available online: http://www.ed.gov/legislation/esea02/).

Sherwood, T. (2000). Where has all the "rural" gone? Rural education research and current federal reform. Journal of Research in Rural Education, 16, 159-167.

Smith, E. (2005). Raising standards in American schools: The Case of No Child Left Behind. Journal of Education Policy, 20, 507-524.

U. S. Government Accountability Office. (2004). No child left behind act: Additional assistance and research on effective strategies would help small rural districts. (GAO-04-909). Washington, D.C.: Author. 